\title{
PRATICANDO GESTÃO DE OPERAÇÕES EM UM LABORATÓRIO DE GESTÃO
}

\begin{abstract}
ROBERTO PORTES RIBEIRO
Doutorando em Administração da Faculdade de Economia, Administração e Contabilidade da Universidade de São Paulo (FEA-USP). Professor assistente II do Centro de Educação Superior do Norte do Rio Grande do Sul da Universidade Federal de Santa Maria (UFSM).
\end{abstract}

Avenida Independência, 3.751, sala 109, Vista Alegre, Palmeira das Missões - RS - Brasil - CEP 98300-000

E-mail: robertor@ufsm.br

ANTONIO CARLOS AIDAR SAUAIA

Doutor em Administração pela Faculdade de Economia, Administração e Contabilidade da Universidade de São Paulo (FEA-USP).

Professor associado III da Faculdade de Economia, Administração e Contabilidade da Universidade de São Paulo (USP). Avenida Professor Luciano Gualberto, 908, sala G-160, Cidade Universitária, São Paulo - SP - Brasil - CEP 05508-010 E-mail: asauaia@usp.br

ADRIANA MAROTTI DE MELLO

Doutora em Engenharia de Produção pela Escola Politécnica da Universidade de São Paulo (USP).

Professora da Faculdade de Economia, Administração e Contabilidade da Universidade de São Paulo (FEA-USP).

Avenida Professor Luciano Gualberto, 908, sala E-199, Cidade Universitária, São Paulo - SP - CEP 05508-010

E-mail: adriana.marotti@usp.br

\section{ALVAIR SILVEIRA TORRES JÚNIOR}

Doutor em Comunicação pela Faculdade de Comunicação da Universidade Metodista de São Paulo (Unesp).

Professor da Faculdade de Economia, Administração e Contabilidade da Universidade de São Paulo (FEA-USP).

Avenida Professor Luciano Gualberto, 908, sala G-155, Cidade Universitária, São Paulo - SP - CEP 05508-010

E-mail: alvair@usp.br

I Os autores agradecem ao Conselho Nacional de Desenvolvimento Científico e Tecnológico (CNPq) o auxílio financeiro que possibilitou a realização desta pesquisa.

Este artigo pode ser copiado, distribuído, exibido, transmitido ou adaptado desde que citados, de forma clara e explícita, o nome da revista, a edição, o ano e as páginas nas quais o artigo foi publicado originalmente, mas sem sugerir que a RAM endosse a reutilização do artigo. Esse termo de licenciamento deve ser explicitado para os casos de reutilização ou distribuição para terceiros. Não é permitido o uso para fins comerciais. 


\section{RESUMO}

Descrever modelos de gestão de operações não é suficiente para ilustrar o dinamismo, a complexidade e a importância dessa atividade. As dificuldades de balanceamento entre teoria e prática na formação em gestão de operações sugerem a busca por iniciativas capazes de proporcionar um ambiente de aprendizagem que integre teoria e prática. Desse modo, objetiva-se verificar os temas referentes à gestão de operações pesquisados no ambiente do laboratório de gestão, os principais fatores condicionantes da escolha dos temas e o potencial do laboratório de gestão para a prática dos modelos de gestão de operações. Este estudo aborda os modelos de gestão de operações ligados aos temas estratégia em operações, gestão de cadeia de suprimentos, gestão da qualidade, manutenção, lean production (produção enxuta), sustentabilidade, gestão de processos e produtos, inovação, gestão de estoques, capacidade de produção, teoria das restrições, planejamento e controle da produção, custos de produção, projeto e medida do trabalho, enterprise resource planning/manufacturing resource planning (ERP/MRP - planejamento de recursos empresariais/planejamento de recursos de manufatura), carteira de projetos e o laboratório de gestão apoiado no tripé conceitual: simulador, jogo de empresas e pesquisa aplicada. De acordo com a classificação proposta por Gonçalves (2007), foi realizada uma análise descritiva do laboratório de gestão, na qual se adotou o método de estudo de caso longitudinal, com abordagem quantitativa, na perspectiva de uma pesquisa bibliométrica. Os dados coletados e analisados correspondem a nove anos (2005-2013) de condução do laboratório de gestão em uma universidade pública. O simulador utilizado no laboratório de gestão permitiu aos estudantes gerenciar cinco variáveis de operações explicitamente, o que facilitou $42 \%$ das pesquisas em torno desses temas. Variáveis não explícitas no simulador foram trabalhadas em $58 \%$ das pesquisas aplicadas que exploraram i4 novos temas devido ao jogo de empresas. No entanto, existem variáveis não abordadas nas pesquisas aplicadas e que poderiam ser utilizadas no ambiente do laboratório de gestão. Verificou-se a utilidade do laboratório de gestão para a prática de conceitos de gestão de operações, indicando possíveis avanços na área de ensino e aprendizagem de gestão de operações com a pesquisa 
em torno de temas pouco pesquisados ou ainda não pesquisados nesse ambiente de educação gerencial.

\section{PALAVRAS-CHAVE}

Gestão de operações. Laboratório de gestão. Aprendizagem. Jogos de empresas. Simulador.

\section{INTRODUÇÃO}

A busca de educação gerencial continuada recai sobre uma característica importante no processo de aprendizagem que é aprender por meio da experiência prática. Conforme Senge (2005), quando se age em um sistema complexo como as organizações, as consequências das ações realizadas não são imediatas nem precisas, estando muitas vezes distantes dos autores no tempo e no espaço. Isso implica um dilema: aprende-se melhor a partir da experiência, mas as consequências dessas ações podem não ser experimentadas. Mesmo que as consequências possam ser experimentadas, podem trazer resultados indesejáveis. Como alternativa para o aproveitamento da aprendizagem pela prática, sem incorrer nos riscos que esta pode acarretar, existe a possibilidade de utilizar ambientes virtuais que possibilitem aos envolvidos agir de maneira semelhante à vida real. No que tange à aprendizagem empresarial, esse ambiente virtual é conhecido como jogo de empresas.

O jogo de empresas é um dos conceitos que formam o tripé conceitual formado por simulador, jogo de empresas e pesquisa aplicada, que caracteriza o método inovador denominado laboratório de gestão concebido por Sauaia (20I0). Segundo esse autor, o laboratório de gestão é um ambiente de prática conceitual das teorias de administração, contabilidade e economia, em que se promove aprendizagem vivencial segundo o modelo de Kolb (I984) com significados, no qual o aprender fazendo é peça fundamental, combinando educação gerencial e pesquisa aplicada.

A gestão de operações é uma das atividades mais importantes nos sistemas produtivos organizacionais segundo Slack (2005) e Hayes, Pisano, Upton e Wheelwright (2008), que ressaltaram a importância estratégica das operações em seus estudos. Sprague (2007) discutiu a evolução desse campo de estudo através do tempo, desde a administração científica preconizada por Taylor, passando pela gestão de fábrica, pela gestão industrial, comum em I930, pela gestão da produção, desde a Segunda Guerra Mundial, até chegar à gestão de operações, o campo de estudo mais recente. A maneira como os planos e as estratégias de operações são traçados e implementados dita quão eficiente o sistema produtivo pode ser em atender a uma demanda de mercado. Vários modelos de gestão 
podem ser explorados nesse campo do conhecimento. Entretanto, não é suficiente o administrador do sistema produtivo saber que existem diferentes modelos de gestão de operações. Além de conhecê-los, é necessário aplicá-los de acordo com seus relacionamentos, benefícios e limitações.

Descrever os modelos de gestão de operações não é suficiente para ilustrar o dinamismo, a complexidade e a importância dessa atividade. As dificuldades de balanceamento entre teoria e prática na formação em gestão de operações sugerem a busca por iniciativas capazes de proporcionar um ambiente de aprendizagem que integre teoria e prática.

Para amenizar esse problema e adquirir conhecimento prévio sobre como, onde e dentro de qual escopo esses modelos podem ser aplicados, uma das soluções pode ser a utilização do laboratório de gestão para vivenciar os potenciais problemas práticos que possam ser enfrentados. Nesse contexto, o presente estudo visa contribuir para a aprendizagem sobre temas de gestão de operações, especificamente, verificando os temas referentes à gestão de operações pesquisados no ambiente do laboratório de gestão, os principais fatores condicionantes da escolha dos temas e o potencial do laboratório de gestão para a prática dos modelos de gestão de operações.

Para o alcance desses objetivos, o artigo está distribuído em seis partes, sendo esta introdutória. A seção a seguir trata de uma revisão bibliográfica acerca dos temas gestão de operações e laboratório de gestão. A terceira parte apresenta os aspectos metodológicos da pesquisa, e o quarto tópico explora os temas referentes à gestão de operações pesquisados no ambiente do laboratório de gestão, bem como os principais fatores condicionantes da escolha dos temas. A quinta seção apresenta a discussão dos resultados com foco no potencial do laboratório de gestão para a prática dos modelos de gestão de operações, e, por fim, apresentam-se as considerações finais com conclusões, contribuições, limitações e proposições para novos estudos.

\section{GESTÃO DE OPERAÇÕES NO CONTEXTO DO LABORATÓRIO DE GESTÃO}

A evolução mundial dos jogos de empresas durante os últimos 40 anos pode ser acompanhada em Faria, Hutchinson, Wellington e Gold (2009). Apesar do fato de a maior parte dos jogos de empresas abordar processos generalistas de gestão, há estudos sobre o uso de jogos como ferramenta de treinamento em áreas específicas, como logística, operações, contabilidade, finanças, administração rural, marketing, gestão de pessoas, custos, mercado de capitais etc. Entre essas áreas, a de gestão de operações destaca-se pela maior quantidade de 
simuladores em jogos de empresas. Nesta seção, tem-se por objetivo realizar a fundamentação teórica sobre os temas gestão de operações e laboratório de gestão concebido a partir dos jogos de empresas.

\subsection{GESTÃO DE OPERAÇÕES}

De acordo com a perspectiva de Hayes et al. (2008), os recursos operacionais e tecnológicos podem ser estrategicamente gerenciados para alcançar uma vantagem competitiva. A ênfase atual no campo de gestão de operações deve ser menos direcionada a ferramentas e técnicas específicas, que tendem a ser sensíveis a diferenças culturais, e mais voltada a uma estrutura (framework) global para pensar sobre o gerenciamento de uma função de operações na empresa. Ao longo dos anos, surgiram muitos esforços no sentido da avaliação e implementação de excelência de operações por meio de vários frameworks.

Slack (2005) reconhece que, embora nas últimas três décadas tenha sido constatado um crescimento na percepção de importância da área de estratégia de operações, juntamente com a sua respectiva base literária, pode-se argumentar que ela ainda não atingiu todo o seu potencial. O autor indica algumas das razões pelas quais isso pode estar ocorrendo e explora alguns dos desafios para transformar tópicos relacionados a operações em tópicos com importância estratégica.

Para classificar o interesse em pesquisa na área de gestão de operações, Slack, Lewis e Bates (2004) compararam os temas abordados em artigos publicados nos dois principais journals americano e europeu sobre gestão de operações, com algumas medidas de práticas prioritárias. Essas práticas prioritárias para profissionais foram avaliadas a partir dos dados de uma pesquisa anual de MBAs da Universidade de Warwick. Essa pesquisa originalmente reportada em Slack et al. (2004) foi estendida para incluir mais dados e abrange o período de $2000 \mathrm{a}$ 2005. As avaliações sobre a importância de cada um dos I 6 tópicos foram enquadradas em termos de percepções individuais, com base na experiência anterior, do impacto que esses assuntos têm no desempenho geral do negócio. O Quadro I mostra a comparação entre os resultados, em que se verificou o desalinhamento entre teoria e prática profissional.

Slack, Chambers e Johnston (2008) enfatizam que os tópicos abordados em gestão de operações oferecem potencial para aumentar receitas e, ao mesmo tempo, facilitam que bens e serviços sejam produzidos de forma mais eficiente, combinando maior receita e custos mais baixos, o que se mostra importante para qualquer empresa. Segundo os autores, o entendimento do papel estratégico que a produção pode e deve ter na busca dos objetivos globais da empresa está relacionado com o alcance de cinco objetivos de desempenho: qualidade, rapidez, confiabilidade, flexibilidade e custos. 


\section{QUADRO I}

COMPARAÇÃO ENTRE PRÁTICAS PRIORITÁRIAS PARA A PESQUISA E PARA PROFISSIONAIS

\begin{tabular}{|c|c|c|c|}
\hline MÉDIA PRÁTICA & $\begin{array}{l}\text { PRÁT. ENTREVISTA MBA } \\
(2000-2005)\end{array}$ & $\begin{array}{l}\text { PRÁT. PESQUISADA }\left(\mathrm{JOM}^{*}+\text { IJOPM }^{* *}\right) \\
\text { 2000-2003 }\end{array}$ & ARTIGOS (\%) \\
\hline 4,51 & Qualidade & Estratégia de operações & 20,25 \\
\hline 4,44 & Cadeia de suprimentos & Cadeia de suprimentos & 14,93 \\
\hline 4,15 & JIT/lean & Qualidade & 10,45 \\
\hline 4,00 & MRP/ERP & Medição de performance & 7,14 \\
\hline 3,97 & Planejamento e controle & Tecnologia de processo & 6,63 \\
\hline 3,69 & Projeto de processos & Projeto de produto/serviço & 6,45 \\
\hline 3,35 & Estratégia de operações & Projeto do trabalho & 5,06 \\
\hline 3,33 & Capacidade & JIT***/lean & 3,97 \\
\hline 3,12 & Medição de performance & Planejamento e controle & 3,75 \\
\hline 3,00 & Estoque & Projeto de processos & 2,64 \\
\hline 3,00 & Projeto de produto/serviço & Estoque & 1,86 \\
\hline 3,00 & Tecnologia de processo & Falhas/risco & 1,49 \\
\hline 2,85 & Projeto do trabalho & Manutenção & 0,81 \\
\hline 2,58 & Falhas/Risco & Capacidade & 0,63 \\
\hline 1,92 & Manutenção & Layout & 0,33 \\
\hline 1,63 & Layout & MRP/ERP & 0,31 \\
\hline
\end{tabular}

* JOM - Journal of operations management

** IJOPM - International journal of operations and production management $* * *$ JIT - Just in time

Fonte: Slack (2005, p. 324).

No contexto brasileiro, Paiva e Brito (20I3) analisaram temas de pesquisa abordados por pesquisadores brasileiros da área de gestão de operações, no período de 2000 a 20I0, nas principais revistas brasileiras da área de administração e nos periódicos internacionais mais relevantes da área de gestão de operações, e encontraram convergência entre o que foi publicado pelos autores brasileiros no Brasil e nos periódicos estrangeiros, destacando os temas apresentados no Quadro 2. 
QUADRO 2

TEMAS PRIORITÁRIOS PARA A PESQUISA NO BRASIL

\begin{tabular}{lc|}
\hline TEMA & NÚMERO DE ARTIGOS \\
\hline Supply chain management & 29 \\
\hline Estratégia de operações & 14 \\
\hline Desenvolvimento de produtos & 13 \\
\hline Programação da produção & 8 \\
\hline Operações de serviços & 6 \\
\hline Gestão da qualidade & 5 \\
\hline Desempenho em operações & 2 \\
\hline Gestão da variedade de produtos & 1 \\
\hline Operações sustentáveis & \\
\hline
\end{tabular}

Fonte: Paiva e Brito (2013, pp. 59-60).

Com enfoque nos processos produtivos adotados por empresas instaladas no Brasil, Peinado e Graeml (20I3) identificaram os temas de gestão de operações que estão sendo valorizados atualmente pelas empresas mais expressivas na criação, utilização e disseminação de novos conceitos produtivos. Os conteúdos dos principais documentos que direcionam o sistema de produção adotado pelas empresas estudadas revelaram os temas prioritários para as organizações: sistemas de produção enxuta; gerenciamento da qualidade; gerenciamento de pessoas em operações; gerenciamento de processos; projeto, medida e melhoria do trabalho; e mensuração do desempenho e produtividade.

As semelhanças e diferenças na percepção dos temas mais relevantes da gestão de operações a partir das perspectivas da pesquisa e da prática foram identificadas, respectivamente, nos estudos de Paiva e Brito (2013) e Peinado e Graeml (20I3), procurando compreender seus motivos e implicações. Isso implica o questionamento dos temas que deveriam ser priorizados no ensino e na aprendizagem de gestão de operações e seu relacionamento com pesquisa e prática empresarial.

Uma revisão da literatura foi realizada por Sharma e Kodali (2008) para fornecer um breve resumo sobre 23 frameworks de excelência em manufatura de classe mundial propostos por vários pesquisadores, consultores e agências internacionais. Os autores propõem um novo framework para a excelência em manufatura por meio da análise comparativa dos quadros existentes, juntamente com o domínio do conceito de excelência em manufatura e pela discussão com 
especialistas. Os I2 pilares do framework são mostrados no Quadro 3, em que aparecem temas ligados a gestão de pessoas e marketing.

\section{QUADRO 3}

PILARES DO FRAMEWORK DE EXCELÊNCIA EM OPERAÇÕES

\begin{tabular}{lll}
\hline ESTRATÉGIA DE OPERAÇÕES & LIDERANÇA & GESTÃO DO CONHECIMENTO \\
\hline Manufatura verde & Gestão de recursos humanos & Processos flexíveis \\
\hline $\begin{array}{l}\text { Gestão da cadeia de } \\
\text { suprimentos }\end{array}$ & $\begin{array}{l}\text { Gestão do relacionamento } \\
\text { com consumidor (customer } \\
\text { relationship management - CRM) }\end{array}$ & $\begin{array}{l}\text { Planejamento de produtos } \\
\text { inovadores }\end{array}$ \\
\hline Gestão da qualidade total & $\begin{array}{l}\text { Sistemas de manutenção de } \\
\text { classe mundial }\end{array}$ & Manufatura enxuta \\
\hline
\end{tabular}

Fonte: Sharma e Kodali (2008, p. 60).

Frameworks diferentes são encontrados para determinar iniciativas comuns. A identificação de elementos comuns e adição de alguns tópicos mais essenciais para proporcionar um melhor enquadramento do que é relevante para o atual cenário global se encontram fragmentados em estudos de autores focados em determinados temas como exemplificado no Quadro 4.

QUADRO 4

PRINCIPAIS TEMAS DE GESTÃO DE OPERAÇÕES

\begin{tabular}{ll}
\hline TEMAS DE GESTÃO DE OPERAÇÕES & PRINCIPAIS AUTORES \\
\hline \multirow{2}{*}{ Tomada de decisões em operações } & Gino e Pisano (2008) \\
\cline { 2 - 2 } & Caro et al. (2010) \\
\hline Estratégias em operações & Barney (1995) \\
& Slack (2005) \\
\hline & Gautam, Kadyan e Ohlan (2012) \\
\hline Lean production & Womack e Jones (1996) \\
\cline { 2 - 2 } & Shah e Ward (2003) \\
\cline { 2 - 2 } & Baudin (2010) \\
\hline
\end{tabular}

(continua) 


\section{QUADRO 4 (CONCLUSÃO)}

PRINCIPAIS TEMAS DE GESTÃO DE OPERAÇÕES

\begin{tabular}{ll}
\hline TEMAS DE GESTÃO DE OPERAÇÕES & PRINCIPAIS AUTORES \\
\hline Inovação em gestão de operações & \multicolumn{1}{c}{ Christensen, Suárez e Utterback (1998) } \\
\cline { 2 - 2 } Zilbovicius (1999) \\
\cline { 2 - 2 } Gestão da cadeia de suprimentos & Halldorsson, Kotzab, Mikkola e Larsen (2007) \\
\hline Operações e sustentabilidade & Gonçalves (2009) \\
\hline ERPs & Kleindorfer, Singhal e Wassenhove (2005) \\
\hline Jabbour, Silva, Paiva e Santos (2012) \\
\hline Carteira de projetos & Sharma e Kodali (2008) \\
\hline Gestão da qualidade & Cooper, Edgett e Kleinschmidt (2001) \\
\hline & Nascimento (2013) \\
\hline & Minkman, Ahaus e Huijsman (2007) \\
\hline & Llach, Casadesus e Marimon (2011) \\
\hline
\end{tabular}

Fonte: Elaborado pelos autores.

O conceito de operações de classe mundial e os seus elementos têm sido minuciosamente estudados de modo a proporcionar uma perspectiva relevante na excelência de manufatura, em que se busca ser o melhor em cada uma das prioridades competitivas e demonstrar as melhores práticas da indústria.

\subsection{LABORATÓRIO DE GESTÃO}

Bloom e Reenen (20I0), em seus estudos, concluem que a educação está fortemente correlacionada com altos escores de gestão, no que tange ao nível de escolaridade dos gestores e/ou dos trabalhadores. Não se pode inferir uma relação causal a partir dessa associação, mas é plausível que os gestores com graduação e/ou pós-graduação são mais propensos a considerar os benefícios de modernas práticas de gestão, como a manufatura enxuta. Sendo assim, a educação gerencial mostra-se relevante no contexto econômico atual de elevada competitividade. 
Severino (2007) destaca as mudanças no contexto educacional impostas pela evolução da sociedade, em que o conhecimento deve ser construído pela experiência ativa do estudante e não mais ser assimilado passivamente. Entretanto, Bligh (2000) analisou os resultados de pesquisas em que se comparou a exposição com outros métodos de ensino-aprendizagem e concluiu que não há diferenças significativas quanto à eficácia dos diferentes métodos no que se refere à aquisição de informações. Gil (2009) refere-se às aulas expositivas como o mais antigo e ainda o mais utilizado método de ensino e expõe os motivos pelos quais as aulas expositivas são tão utilizadas, discutindo vantagens e limitações da exposição.

Entre os métodos de ensino-aprendizagem, encontram-se os jogos de empresas como alternativa às aulas expositivas. Sauaia (I995) abordou os jogos de empresas como um recurso valioso que pode contribuir para o avanço da educação gerencial, se bem explorado e por combinar satisfação com aprendizagem. Summers (2004) destaca que o uso de novas tecnologias transformou e impulsionou o processo de criação e elaboração de novos jogos de empresas. Tao, Cheng e Sun (2009) reforçam a importância dos jogos de empresas em sua pesquisa sobre o que motiva os estudantes a continuar participando de jogos de empresas.

Sauaia (2006) aponta que a aprendizagem no jogo de empresas resulta da prática conceitual em um trabalho de grupo, sujeito aos diferentes níveis de envolvimento dos membros de cada grupo. Cada participante, ao assumir um papel gerencial em uma área funcional, seleciona um tema de investigação e o transforma em pesquisa aplicada ao jogo de empresas, tornando-o um laboratório de experimentos controlados em busca de aprofundamento conceitual e criação de conhecimento para adicionar valor para a empresa e para o indivíduo.

Seguindo essa linha de raciocínio, foi concebido por Sauaia (20I0) um método ativo denominado laboratório de gestão apoiado em três componentes conceituais - simulador organizacional, jogo de empresas e pesquisa aplicada que permitiram inovar a condução dos jogos de empresas inserindo a pesquisa aplicada no transcorrer do jogo de empresas. Esses componentes foram classificados e explicados por Sauaia (2010) conforme o Quadro 5.

\section{QUADRO 5}

\section{COMPONENTES DO LABORATÓRIO DE GESTÃO}

\begin{tabular}{ll}
\hline COMPONENTES & CONCEITOS \\
\hline $\begin{array}{l}\text { Simulador } \\
\text { organizacional }\end{array}$ & Situação inicial da organização descrita por meio de regras econômicas \\
\hline Jogo de empresas & Vivência organizacional em um processo de tomada de decisão sob incerteza \\
\hline Pesquisa aplicada & Experiência individual relatada em um artigo \\
\hline
\end{tabular}

Fonte: Sauaia (2010, p. 3). 
O laboratório de gestão adota um simulador organizacional geral parametrizável constituído por um conjunto de regras econômicas a serem praticadas para exercitar teorias, conceitos e técnicas que aborda seis áreas funcionais: planejamento, marketing, produção, pessoas, finanças e presidência, cuja complexidade pode ser dimensionada pelo educador. A operacionalização e dinamização do simulador apoia o jogo de empresas, um processo de tomada de decisão sob incerteza, no qual a análise de resultados permite estabelecer relações de causa e efeito. Os resultados produzidos nesse ambiente de aprendizagem dinâmica são objeto de pesquisas teórico-empíricas relatadas pelos estudantes em artigos (Sauaia, 20Io).

Dessa forma, cada estudante que participa do jogo de empresas é responsável por identificar um problema de pesquisa para investigar em sua área funcional. Conforme Sauaia (20I0), a investigação científica no laboratório de gestão baseia-se em modelos conceituais para aportar teorias à tomada de decisão no jogo de empresas, criando novos significados e adicionando valor à organização. O produto dessa pesquisa se apresenta ao final de um semestre como um artigo formatado conforme roteiro intitulado monografia racional eletrônica concebido por Sauaia (2009).

A Figura I demonstra por meio de um fluxograma o funcionamento do laboratório de gestão, em que o caso empresarial é apresentado inicialmente de acordo com as regras econômicas do simulador organizacional, e as análises econômicas conduzidas sob certeza e as apostas estratégicas sob incerteza são realizadas pelos gestores das empresas no processo de tomada de decisão, com os resultados avaliados na forma de indicadores de desempenho a cada rodada do jogo de empresas. Esse fluxo proporcionado pelo simulador em conjunto com o jogo de empresas gera dados primários para as pesquisas aplicadas que tratam de problemas de pesquisa que se referem às questões vivenciadas no transcorrer do jogo de empresas.

FIGURA I

FLUXOGRAMA DO LABORATÓRIO DE GESTÃO

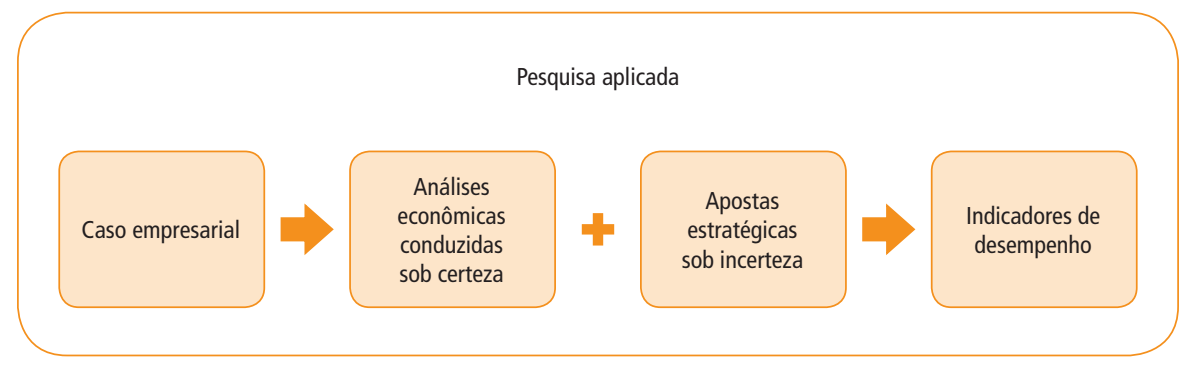

Fonte: Adaptada de Sauaia (2010, p. 5). 
No ambiente do laboratório de gestão, enquanto os conceitos estáticos no livro presentes na descrição das regras do simulador são ativados no jogo de empresas, a pesquisa aplicada é materializada de maneira individual com base na aprendizagem coletiva. Os relatórios produzidos em formato científico descrevem a compreensão sistêmica alcançada por cada participante. São produzidos resultados esperados e inesperados que devem ser discutidos com embasamento em modelos teóricos para produzir um texto crítico de reflexão (Sauaia, 20Io). Sendo assim, essa inovação, concebida por Sauaia (20I0) ao longo de 27 anos de experiência acadêmica, que combina educação gerencial e pesquisa aplicada traz um ambiente de prática conceitual que pode ser aproveitado com ênfase maior à gestão de operações.

\subsection{GESTÃO DE OPERAÇÕES E LABORATÓRIO DE GESTÃO}

Slack (2005) verificou um desalinhamento entre o interesse em pesquisa na área de gestão de operações e práticas prioritárias para profissionais, o que demonstrou que teoria acadêmica e prática profissional necessitam de maior aproximação. Nesse sentido, surge o laboratório de gestão concebido por Sauaia (20I0) como uma maneira de aproximar a academia e as organizações, utilizando um simulador organizacional que apoia um jogo de empresas e gera dados primários para pesquisas aplicadas em seis áreas funcionais, entre elas a gestão de operações.

Alcançar vantagem competitiva com o gerenciamento estratégico de recursos operacionais e tecnológicos mostra-se um desafio conforme Hayes et al. (2008) que destacaram a importância das outras funções organizacionais que interagem com operações, uma vez que transformar as operações em fonte de vantagem competitiva requer o envolvimento de todos. Nesse sentido, o laboratório de gestão pode ser uma alternativa para que gestores de outras áreas se aproximem e conheçam o ambiente de operações de uma organização.

Frameworks de excelência em manufatura propostos por vários pesquisadores, consultores, agências e empresas podem direcionar novas variáveis de operações para o simulador utilizado no laboratório de gestão, no sentido de focalizar temas relevantes à gestão de operações não abordados ou abordados superficialmente no ambiente do laboratório de gestão. No jogo de empresas, a adição de alguns tópicos que proporcionem um melhor enquadramento do que é relevante para o atual cenário de operações poderia ser considerada no contexto do laboratório de gestão. 


\section{MÉTOdo de PESQUISA}

Gonçalves (2007) apresentou uma classificação baseada nos objetivos, nos procedimentos de coleta de dados, nas fontes de informação de pesquisa e na natureza dos dados. O Quadro 6 expõe a classificação dos diversos tipos de pesquisa conforme a orientação da autora.

QuAdro 6

TIPOS DE PESQUISA

\begin{tabular}{cccc}
\hline OBJETIVOS & PROCEDIMENTOS & FONTES DE INFORMAÇÃO & NATUREZA DOS DADOS \\
\hline Exploratória & Experimento & Campo & Quantitativa \\
\hline Descritiva & Levantamento & Laboratório & Qualitativa \\
\hline Experimental & Estudo de caso & Bibliográfica & \\
\hline Explicativa & Bibliográfica & Documental & \\
\hline & Documental & & \\
\hline & Participativa & \\
\hline
\end{tabular}

Fonte: Gonçalves (2007, p. 66).

Seguindo a classificação proposta por Gonçalves (2007), caracteriza-se esta pesquisa como descritiva quanto aos objetivos, adotando o método de estudo de caso longitudinal como procedimento de pesquisa, com uso de documentos do laboratório de gestão como fontes de informação, e fazendo uso de dados de natureza quantitativa na perspectiva de uma pesquisa bibliométrica. Conforme Araújo (2006), a bibliometria realiza uma avaliação objetiva da produção científica por meio de métodos quantitativos, descrevendo aspectos da literatura pela aplicação de técnicas estatísticas e matemáticas. Os aspectos analisados variam conforme a análise e podem ser os seguintes: a frequência de publicações por ano, autor e periódico, e o número de citações dos artigos em bases de dados. A partir de dados secundários da revisão de literatura acerca dos temas gestão de operações e laboratório de gestão concebido a partir dos jogos de empresas, partiu-se para a coleta dos dados primários nas pesquisas aplicadas na área de gestão de operações de 2005 a 2013, o que corresponde a nove anos de condução do laboratório de gestão nos cursos de graduação em Administração e Contabilidade de uma universidade pública. 
As pesquisas aplicadas foram geradas pelos gestores da função produção e de outras funções correlatas que estudaram questões da gestão de operações relacionadas à sua área de atuação, em uma empresa participante de um jogo de empresas apoiado por um simulador empresarial, especificamente o Simulab, usado como plataforma de aprendizagem com o intuito de propiciar um ambiente de tomada de decisões e aproximar o ambiente acadêmico do jogo de empresas da realidade organizacional. Os dados das empresas no transcorrer do jogo, ou seja, relatórios do jogo de empresas, observação de notícias, fatos, comportamento das empresas concorrentes e acontecimentos em sala de aula, serviram de base para praticar os conceitos de gestão de operações. A partir das pesquisas aplicadas, foi possível levantar os temas referentes à gestão de operações pesquisados no ambiente do laboratório de gestão.

As variáveis referentes à gestão de operações do modelo econômico do simulador Simulab utilizado no laboratório de gestão - contexto do jogo de empresas, conhecimentos, habilidades e atitudes do professor, e acontecimentos inesperados (fatos novos) no andamento do jogo de empresas - foram analisadas nas pesquisas aplicadas e relacionadas como os principais fatores condicionantes da escolha de determinados temas de pesquisa em gestão de operações no ambiente do laboratório de gestão, embasando os resultados e as conclusões desta pesquisa.

\section{RESULTADOS}

O jogo de empresas nas turmas de graduação se deu em uma condição em que algumas empresas, em torno de cinco a $\mathrm{I} 4$, produziam e comercializavam o mesmo produto tecnológico em um mercado, formando um oligopólio. Durante oito trimestres, às vezes, nove trimestres, que representam aproximadamente dois anos de operações, as decisões foram tomadas por um grupo que geralmente possuía seis diretores que representam seis áreas funcionais: presidência, planejamento, gestão de pessoas, marketing, finanças e produção. As decisões com variáveis mercadológicas, operacionais e financeiras eram processadas e produziam, em ciclos trimestrais, demonstrativos das operações e financeiros (demonstrativo de lucros e perdas, do fluxo de caixa e balanço patrimonial) que eram utilizados pelos diretores para gerenciar as empresas.

No transcorrer do jogo de empresas, a prática de diversos conceitos em cada uma das áreas funcionais, em um trabalho de grupo, ocorreu de acordo com o envolvimento dos membros de cada grupo. Assim, cada participante do grupo assumiu um papel gerencial em uma área funcional, selecionou um tema de investigação e o transformou em pesquisa aplicada ao jogo de empresas. Este estudo focalizou as pesquisas aplicadas que foram geradas pelos gestores da 
função produção e outras funções correlatas que estudaram questões da gestão de operações relacionadas à sua área de interesse em uma empresa participante do jogo de empresas.

Neste estudo de caso longitudinal, foram elencadas I.463 pesquisas aplicadas elaboradas no âmbito do laboratório de gestão que correspondem a II semestres de condução do laboratório em 32 turmas de graduação em Administração e Contabilidade no período de nove anos, desde o segundo semestre de 2005 até o primeiro semestre 2013. Foram selecionadas 243 pesquisas aplicadas da área de gestão de operações, correspondendo a i $6,6 \%$ do total de pesquisas aplicadas registradas na forma de artigos concebidas nesse período. O Gráfico I mostra a quantidade de pesquisas no decorrer do tempo.

\section{GRÁFICO I}

PESQUISAS DE GESTÃO DE OPERAÇÕES NO LABORATÓRIO DE GESTÃO $(2005 / 2-2013 / I)$

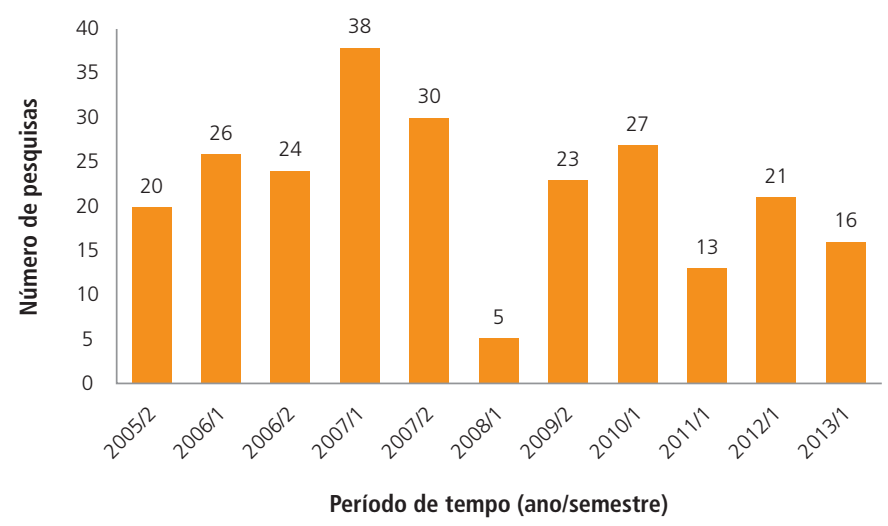

Fonte: Elaborado pelos autores.

\subsection{TEMAS DE GESTÃO DE OPERAÇÕES PESQUISADOS NO AMBIENTE DO LABORATÓRIO DE GESTÃO}

As 243 pesquisas aplicadas da área de gestão de operações foram analisadas e classificadas de acordo com o tema principal de estudo apontado no título de cada pesquisa. A classificação considerou os diferentes frameworks encontrados na literatura para determinar iniciativas comuns e alguns tópicos essenciais em gestão de operações. Foram encontrados I9 temas de gestão de operações pesquisados no laboratório de gestão. Os temas e a frequência de pesquisas em cada tema podem ser visualizados no Gráfico 2. 


\section{GRÁFICO 2}

\section{TEMAS E FREQUÊNCIA DE PESQUISAS DE GESTÃO DE OPERAÇÕES NO LABORATÓRIO DE GESTÃO}

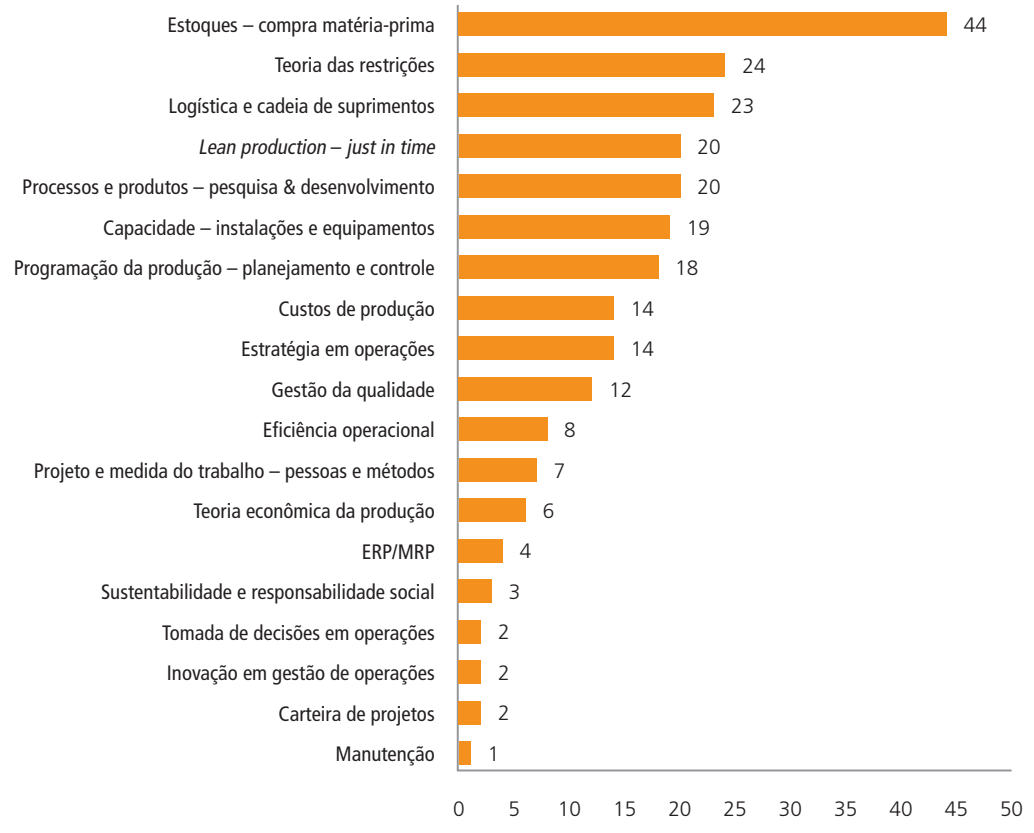

Fonte: Elaborado pelos autores.

A gestão de estoque de matéria-prima e produtos acabados é o tema de gestão de operações mais frequentemente pesquisado no laboratório de gestão, com considerável enfoque no estudo do lote econômico "Compra de matéria-prima", o qual concentra I2 estudos específicos dos 44 estudos de gestão de estoque. Com maior número de pesquisas aplicadas, esse tema representa $18 \%$ do total de pesquisas de gestão de operações no laboratório de gestão.

Os temas teoria das restrições (I०\%), logística e gestão da cadeia de suprimentos $(9 \%)$, lean production e just in time (8\%), gestão de processos e produtos com ênfase em estudos de pesquisa \& desenvolvimento (8\%), gestão da capacidade com investimentos em instalações e equipamentos (8\%) e programação, planejamento e controle da produção com ênfase no uso de horas extras e ativação de turnos de produção (7\%) representam notável percentual de estudos no laboratório de gestão. Em um nível intermediário, aparecem os temas custos de produção (6\%), estratégia em operações $(6 \%)$ e gestão da qualidade $(5 \%)$.

Os temas eficiência operacional (3\%), projeto e medida do trabalho com ênfase na produtividade de pessoas e métodos $(3 \%)$, teoria econômica da pro- 
dução (2\%), ERP/MRP (2\%), sustentabilidade e responsabilidade social em operações (I\%), tomada de decisões em operações (I\%), inovação em gestão de operações (I\%), carteira de projetos (ı\%) e manutenção (ı\%) foram menos abordados em relação aos demais temas de gestão de operações que aparecem nas pesquisas aplicadas do laboratório de gestão.

Após o levantamento dos temas referentes à gestão de operações pesquisados no ambiente do laboratório de gestão, foi realizada uma análise longitudinal ao longo de iI semestres de condução do laboratório de gestão para avaliar a evolução dos temas e as possíveis tendências no transcorrer do tempo. Com base no princípio de que as condições iniciais de utilização do simulador foram iguais nas II aplicações que viabilizaram o funcionamento do jogo de empresas, evidenciou-se que o tema referente à gestão de estoques foi o mais estudado nos cinco períodos iniciais, ou seja, de 2005/I a 2007/2. No período 2008/I, houve uma redução no número de pesquisas aplicadas, pois os estudantes realizaram pesquisas em grupos exclusivamente nesse semestre, em função de um experimento realizado pelo professor. A partir do ano de 2009 , constatou-se maior equilíbrio nos temas pesquisados, sem a preponderância de um único tema, pois, em 2009/2 e 2013/I, o tema referente à teoria das restrições foi o mais pesquisado; em 2010/I e 20I2/I, o tema de lean production obteve o maior número de pesquisas e, em 20II/I, as pesquisas abordaram em maior quantidade o tema de capacidade de instalações e equipamentos. A Tabela I mostra a evolução dos temas no transcorrer do tempo de análise.

TABELA I

\section{EVOLUÇÃO DOS TEMAS DE PESQUISAS DE GESTÃO DE OPERAÇÕES NO LABORATÓRIO DE GESTÃO}

\begin{tabular}{l|c|c|c|c|c|c|c|c|c|c|c|c}
\hline $\begin{array}{l}\text { TEMAS DE GESTÃO } \\
\text { DE OPERAÇÕES }\end{array}$ & $2005 / 1$ & $2006 / 1$ & $2006 / 2$ & $2007 / 1$ & $2007 / 2$ & $2008 / 1$ & $2009 / 2$ & $2010 / 1$ & $2011 / 1$ & $2012 / 1$ & $2013 / 1$ & TOTAL \\
\hline Manutenção & 0 & 0 & 1 & 0 & 0 & 0 & 0 & 0 & 0 & 0 & 0 & 1 \\
\hline Carteira de projetos & 0 & 1 & 1 & 0 & 0 & 0 & 0 & 0 & 0 & 0 & 0 & 2 \\
\hline $\begin{array}{l}\text { Inovação em gestão } \\
\text { de operações }\end{array}$ & 0 & 0 & 0 & 1 & 0 & 0 & 0 & 0 & 0 & 1 & 0 & 2 \\
\hline $\begin{array}{l}\text { Tomada de decisões } \\
\text { em operações }\end{array}$ & 0 & 0 & 0 & 0 & 0 & 0 & 0 & 1 & 0 & 1 & 0 & 2 \\
\hline $\begin{array}{l}\text { Sustentabilidade e } \\
\text { responsabilidade } \\
\text { social }\end{array}$ & 1 & 0 & 0 & 1 & 0 & 1 & 0 & 0 & 0 & 0 & 0 \\
\hline
\end{tabular}


- ROBERTO PORTES RIBEIRO • ANTONIO CARLOS AIDAR SAUAIA

- ADRIANA MAROTTI DE MELLO • ALVAIR SILVEIRA TORRES JÚNIOR •

TABELA I (CONCLUSÃO)

EVOLUÇÃO DOS TEMAS DE PESQUISAS DE GESTÃO

DE OPERAÇÕES NO LABORATÓRIO DE GESTÃO

\begin{tabular}{|c|c|c|c|c|c|c|c|c|c|c|c|c|}
\hline $\begin{array}{l}\text { TEMAS DE GESTÃO } \\
\text { DE OPERAÇÕES }\end{array}$ & $2005 / 1$ & $2006 / 1$ & $2006 / 2$ & $2007 / 1$ & $2007 / 2$ & $2008 / 1$ & $2009 / 2$ & $2010 / 1$ & $2011 / 1$ & $2012 / 1$ & 2013/1 & TOTAL \\
\hline ERP/MRP & 1 & 0 & 0 & 0 & 2 & 0 & 0 & 0 & 1 & 0 & 0 & 4 \\
\hline $\begin{array}{l}\text { Teoria econômica } \\
\text { da produção }\end{array}$ & 0 & 1 & 1 & 0 & 0 & 0 & 1 & 0 & 1 & 2 & 0 & 6 \\
\hline $\begin{array}{l}\text { Projeto e medida } \\
\text { do trabalho - } \\
\text { pessoas e métodos }\end{array}$ & 0 & 0 & 0 & 1 & 0 & 0 & 1 & 3 & 0 & 2 & 0 & 7 \\
\hline $\begin{array}{l}\text { Eficiência } \\
\text { operacional }\end{array}$ & 0 & 0 & 2 & 2 & 1 & 1 & 0 & 0 & 1 & 0 & 1 & 8 \\
\hline $\begin{array}{l}\text { Gestão da } \\
\text { qualidade }\end{array}$ & 0 & 2 & 2 & 0 & 2 & 1 & 1 & 2 & 0 & 0 & 2 & 12 \\
\hline $\begin{array}{l}\text { Estratégia em } \\
\text { operações }\end{array}$ & 1 & 1 & 1 & 5 & 0 & 1 & 2 & 1 & 0 & 1 & 1 & 14 \\
\hline Custos de produção & 0 & 4 & 1 & 1 & 3 & 0 & 1 & 1 & 0 & 2 & 1 & 14 \\
\hline $\begin{array}{l}\text { Programação } \\
\text { da produção - } \\
\text { planejamento e } \\
\text { controle }\end{array}$ & 0 & 1 & 2 & 3 & 4 & 0 & 1 & 3 & 0 & 3 & 1 & 18 \\
\hline $\begin{array}{l}\text { Capacidade - } \\
\text { instalações e } \\
\text { equipamentos }\end{array}$ & 3 & 1 & 3 & 3 & 2 & 0 & 1 & 2 & 4 & 0 & 0 & 19 \\
\hline $\begin{array}{l}\text { Processos e } \\
\text { produtos - pesquisa } \\
\& \text { desenvolvimento }\end{array}$ & 2 & 2 & 2 & 3 & 2 & 1 & 3 & 2 & 2 & 1 & 0 & 20 \\
\hline $\begin{array}{l}\text { Lean production - } \\
\text { just in time }\end{array}$ & 0 & 0 & 0 & 2 & 2 & 0 & 1 & 7 & 1 & 4 & 3 & 20 \\
\hline $\begin{array}{l}\text { Logística e cadeia } \\
\text { de suprimentos }\end{array}$ & 7 & 1 & 2 & 3 & 3 & 0 & 4 & 1 & 1 & 0 & 1 & 23 \\
\hline Teoria das restrições & 0 & 3 & 3 & 3 & 0 & 0 & 4 & 1 & 1 & 3 & 6 & 24 \\
\hline $\begin{array}{l}\text { Estoques - compra } \\
\text { de matéria-prima }\end{array}$ & 5 & 9 & 3 & 10 & 9 & 0 & 3 & 3 & 1 & 1 & 0 & 44 \\
\hline Total & 20 & 26 & 24 & 38 & 30 & 5 & 23 & 27 & 13 & 21 & 16 & 243 \\
\hline
\end{tabular}

Fonte: Elaborada pelos autores. 
O Gráfico 3 permite a visualização da evolução dos sete principais temas pesquisados no âmbito do laboratório de gestão, no transcorrer do tempo de análise, que representam aproximadamente $70 \%$ das pesquisas aplicadas.

\section{GRÁFICO 3}

EVOLUÇÃO DOS SETE PRINCIPAIS TEMAS DE PESQUISAS DE GESTÃO DE OPERAÇÕES NO LABORATÓRIO DE GESTÃO

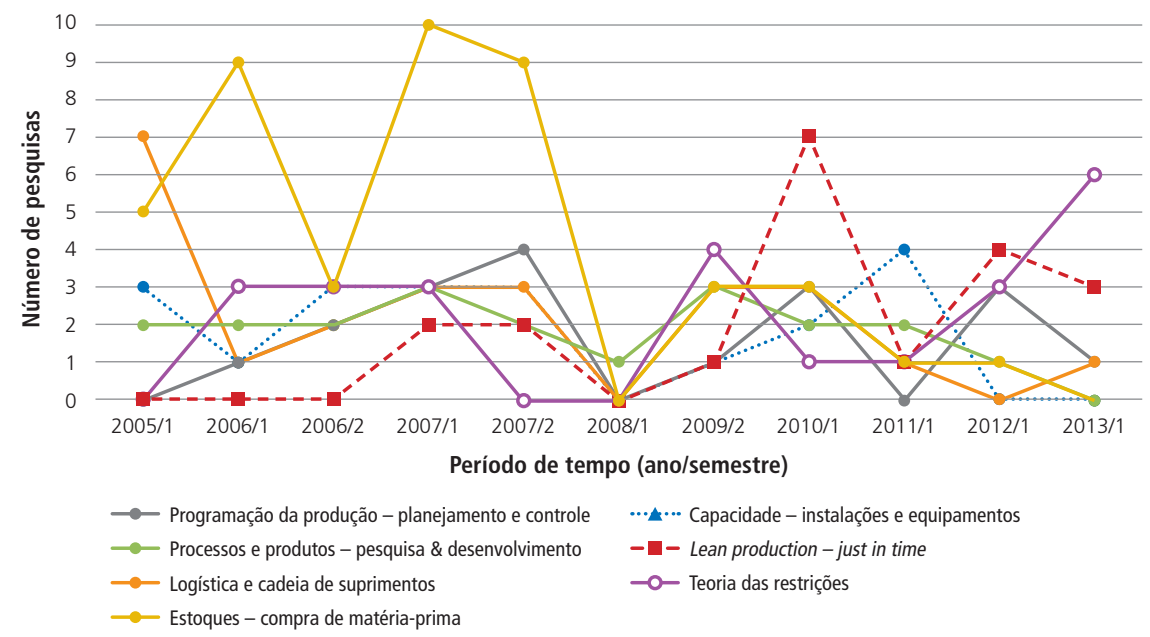

Fonte: Elaborado pelos autores.

\subsection{FATORES CONDICIONANTES DA ESCOLHA DE DETERMINADOS TEMAS DE PESQUISA}

Por meio da análise dos temas de gestão de operações pesquisados no ambiente do laboratório de gestão, permitiu-se investigar os principais fatores condicionantes da escolha dos temas. Portanto, constatou-se que as variáveis referentes à gestão de operações do modelo econômico do simulador utilizado no laboratório de gestão influenciaram a escolha dos temas que são objeto de pesquisas teórico-empíricas realizadas pelos estudantes. O simulador geral parametrizável constituído por um conjunto de regras econômicas a serem praticadas para exercitar teorias, conceitos e técnicas aborda seis áreas funcionais, incluindo a função produção que envolve cinco decisões explicitamente relacionadas com cinco temas abordados nas pesquisas aplicadas. A Tabela 2 mostra a relação entre as variáveis de decisão do simulador e os temas das pesquisas de gestão de operações no laboratório de gestão. 
TABELA 2

ASSOCIAÇÃO ENTRE AS VARIÁVEIS DE DECISÃO DO SIMULADOR

E OS TEMAS DAS PESQUISAS DE GESTÃO DE OPERAÇÕES

NO LABORATÓRIO DE GESTÃO

\begin{tabular}{llcc}
\hline $\begin{array}{l}\text { VARIÁVEL DE DECISÃO } \\
\text { DO SIMULADOR }\end{array}$ & TEMAS DE GESTÃO DE OPERAÇÕES & No DE PESQUISAS & PERCENTUAL \\
\hline Compra de matéria-prima & Gestão de estoques & 44 & $18 \%$ \\
\hline $\begin{array}{l}\text { Gastos em pesquisa \& } \\
\text { desenvolvimento }\end{array}$ & Processos e produtos & 20 & $8 \%$ \\
\hline $\begin{array}{l}\text { Investimentos na fábrica } \\
\text { Volume de produção } \\
\text { programada }\end{array}$ & $\begin{array}{l}\text { Planejamento e controle } \\
\text { da produçãade }- \text { instalações e }\end{array}$ & 19 & $\mathbf{8 \%}$ \\
\hline $\begin{array}{l}\text { Gastos em manutenção } \\
\text { da fábrica }\end{array}$ & Manutenção & 18 & $\mathbf{7 \%}$ \\
\hline & Total & 1 & $\mathbf{4 2 \%}$ \\
\hline
\end{tabular}

Fonte: Elaborada pelos autores.

Verificou-se que $42 \%$ das pesquisas aplicadas estão relacionadas com as cinco variáveis de decisão do simulador referentes à gestão de operações. A decisão de compra de matéria-prima remete ao tema de gestão de estoques, a decisão de gastos em pesquisa e desenvolvimento associa-se ao tema de gestão de processos e produtos, os investimentos em instalações e equipamentos da fábrica relacionam-se com o tema de capacidade de produção, a decisão de volume de produção programada com uso de horas extras e ativação de turnos de operação está relacionada com o tema de planejamento e controle da produção, e os gastos em manutenção da fábrica referem-se ao tema de manutenção. Entre os temas de pesquisa em gestão de operações relacionados com as variáveis de decisão do simulador, observou-se que a compra de matéria-prima é uma variável que desperta maior interesse de investigação; no entanto, os gastos em manutenção da fábrica praticamente não geraram interesse de pesquisa em torno do tema.

A dinamização e operacionalização do simulador apoia o jogo de empresas, um processo de tomada de decisão sob incerteza, no qual a análise de resultados permite estabelecer relações de causa e efeito. Portanto, constatou-se que o jogo de empresas influencia a escolha dos temas que são objeto de pesquisas teórico-empíricas realizadas pelos estudantes, por meio do próprio contexto em que 
ocorre o jogo de empresas; dos conhecimentos, das habilidades e atitudes do professor que conduz o jogo de empresas; e dos acontecimentos inesperados (fatos novos) no andamento do jogo de empresas. A Tabela 3 mostra os temas das pesquisas de gestão de operações no laboratório de gestão condicionados pelo jogo de empresas (contexto, professor e acontecimentos inesperados).

\section{TABELA 3}

TEMAS DAS PESQUISAS DE GESTÃO DE OPERAÇÕES NO LABORATÓRIO DE GESTÃO RELATIVOS AO JOGO DE EMPRESAS

\begin{tabular}{|c|c|c|}
\hline TEMAS DE GESTÃO DE OPERAÇÕES & $N^{\circ}$ DE PESQUISAS & PERCENTUAL \\
\hline Teoria das restrições & 24 & $10 \%$ \\
\hline Logística e cadeia de suprimentos & 23 & $9 \%$ \\
\hline Lean production - just in time & 20 & $8 \%$ \\
\hline Estratégia em operações & 14 & $6 \%$ \\
\hline Custos de produção & 14 & $6 \%$ \\
\hline Gestão da qualidade & 12 & $5 \%$ \\
\hline Eficiência operacional & 8 & $3 \%$ \\
\hline Projeto e medida do trabalho - pessoas e métodos & 7 & $3 \%$ \\
\hline Teoria econômica da produção & 6 & $2 \%$ \\
\hline ERP/MRP & 4 & $2 \%$ \\
\hline Sustentabilidade e responsabilidade social & 3 & $1 \%$ \\
\hline Carteira de projetos & 2 & $1 \%$ \\
\hline Inovação em gestão de operações & 2 & $1 \%$ \\
\hline Tomada de decisões em operações & 2 & $1 \%$ \\
\hline Total & 141 & $58 \%$ \\
\hline
\end{tabular}

Fonte: Elaborada pelos autores.

Verificou-se que $58 \%$ das pesquisas aplicadas estão associadas ao jogo de empresas, distribuídas em I4 temas de gestão de operações. Entre esses temas, destacaram-se teoria das restrições, logística e gestão de cadeia de suprimentos, lean production, estratégia em operações, custos de produção e gestão da qualidade. Ainda existem oito temas de pesquisa em gestão de operações que foram 
abordados em menor quantidade de pesquisas e que evidenciaram a capacidade e flexibilidade do jogo de empresas em envolver uma variedade maior de temas diferentes do que o simulador.

Assim, pode-se afirmar que existem dois principais fatores condicionantes da escolha de determinados temas de pesquisa em gestão de operações. O simulador $(42 \%)$ condiciona a escolha por meio das variáveis referentes à gestão de operações do modelo econômico, e o jogo de empresas (58\%) condiciona a escolha por meio do contexto, dos conhecimentos, das habilidades e atitudes do professor que o conduz e dos acontecimentos inesperados em seu andamento.

No que tange à análise longitudinal ao longo de iı semestres de condução do laboratório de gestão para avaliar a evolução dos temas e as possíveis tendências no transcorrer do tempo, verificou-se que, dentre os fatores condicionantes da escolha de determinados temas de pesquisa em gestão de operações, o simulador apresentou influência semelhante ao contexto do jogo de empresas nos cinco períodos iniciais, ou seja, de 2005/I a 2007/2. No período em que se adquiriu maior experiência na condução do jogo de empresas por parte do professor, ou seja, a partir de 2008/I, o contexto do jogo de empresas foi preponderante para a escolha de determinados temas de pesquisa em gestão de operações. Constatou-se que as variáveis do simulador tendem a apresentar menor importância na escolha dos temas de pesquisa em gestão de operações. No Gráfico 4, é possível acompanhar a evolução dos fatores condicionantes da escolha dos temas de pesquisa em gestão de operações no transcorrer do tempo de análise.

\section{GRÁFICO 4}

EVOLUÇÃO HISTÓRICA DOS FATORES CONDICIONANTES DA ESCOLHA DOS TEMAS DE PESQUISA EM GESTÃO DE OPERAÇÕES NO LABORATÓRIO DE GESTÃO

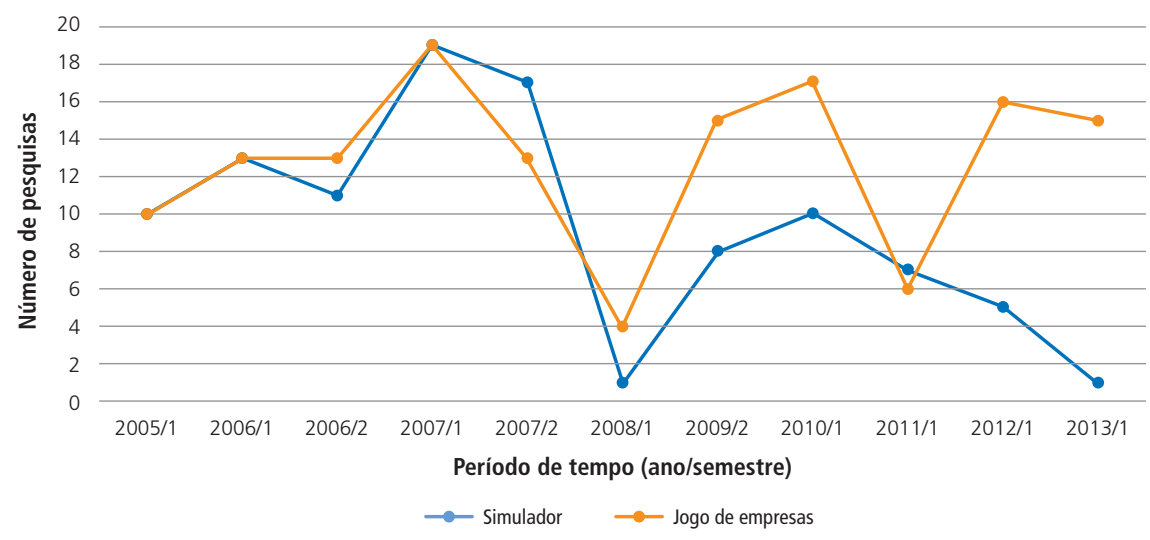

Fonte: Elaborado pelos autores. 


\section{Discussão dos RESULtAdos}

\subsection{POTENCIAL DO LABORATÓRIO DE GESTÃO PARA A PRÁTICA DOS MODELOS DE GESTÃO DE OPERAÇÕES}

Os resultados produzidos no laboratório de gestão, um ambiente de aprendizagem dinâmica, são objeto de pesquisas teórico-empíricas relatadas pelos estudantes em artigos na área de gestão de operações abordando ig temas distintos, o que revelou o potencial do laboratório de gestão para a prática de diferentes modelos de gestão de operações elencados por Slack (2005), Hayes et al. (2008) e Sharma e Kodali (2008).

O simulador utilizado no laboratório de gestão permitiu aos estudantes gerenciar cinco variáveis de operações, explicitamente compra de matéria-prima, gastos em pesquisa $\&$ desenvolvimento, investimentos em instalações e equipamentos, volume de produção programada e gastos em manutenção da fábrica. Isso facilitou a pesquisa em torno de cinco temas: gestão de estoques, gestão de processos e produtos, capacidade de produção, planejamento e controle da produção, e manutenção, reforçando as contribuições de Summers (2004) e Sauaia (2010) que destacaram a importância de novas tecnologias e do simulador para apoiar jogos de empresas. O tema manutenção, apesar de corresponder a uma variável explícita de decisão do simulador, foi objeto de estudo de apenas um estudo, o que revelou um potencial para ser explorado no ambiente do laboratório de gestão.

No entanto, variáveis não explícitas no simulador foram trabalhadas destacadamente nas pesquisas aplicadas, gerando estudos em torno principalmente de seis temas: teoria das restrições, logística e gestão de cadeia de suprimentos, lean production, estratégia em operações, custos de produção e gestão da qualidade. Também foram concebidas pesquisas aplicadas eventualmente em torno de oito temas: eficiência operacional, projeto e medida do trabalho, teoria econômica da produção, ERP/MRP, sustentabilidade e responsabilidade social em operações, tomada de decisões em operações, inovação em gestão de operações e carteira de projetos. Isso demonstrou que o laboratório de gestão foi abrangente e tem potencial para avanços nesses oito temas.

As variáveis não explícitas no simulador foram trabalhadas em razão do contexto em que ocorre o jogo de empresas, dos conhecimentos, das habilidades e atitudes do professor que conduz o jogo de empresas e dos acontecimentos inesperados (fatos novos) no andamento do jogo de empresas, que impõe dinâmica e flexibilidade ao laboratório de gestão para abordar novos temas relacionados à gestão de operações em um método ativo apoiado em três pilares conceituais, que permitiram inovar a condução dos jogos de empresas conforme Sauaia (20I0). 
Existem variáveis não abordadas nas pesquisas aplicadas e que poderiam ser utilizadas para pesquisa acerca dos temas que fazem parte da gestão de operações, tais como projeto de produto, pesquisa operacional, servitização, prevenção e recuperação de falhas, localização de instalações e layout. Slack et al. (2008) abordam esses tópicos e enfatizam sua importância em gestão de operações.

A partir da análise longitudinal ao longo de iI semestres de condução do laboratório de gestão, foi possível avaliar a evolução dos temas e as tendências no transcorrer do tempo que indicaram o tema referente à gestão de estoques como o mais estudado nos cinco períodos iniciais, ou seja, de 2005/I a 2007/2. Um fator preponderante para utilização desse tema nas pesquisas deve-se ao fato de o simulador que apoia o jogo de empresas considerar a encomenda da matéria-prima em um período anterior à sua utilização, o que eventualmente gera falta de matéria-prima, tornando-se um problema gerencial no transcorrer do jogo de empresas e consequentemente ocasionando interesse de pesquisa. Nesse período, verificou-se que, dentre os fatores condicionantes da escolha de determinados temas de pesquisa em gestão de operações, o simulador apresentou influência semelhante ao contexto do jogo de empresas. A análise desse período na Tabela I e no Gráfico 3 depreende estabilização de determinados temas mais pesquisados.

A partir do ano de 2009 , constatou-se maior equilíbrio nos temas pesquisados, sem a preponderância de um único tema, pois, em 2009/2 e 20I3/I, o tema referente à teoria das restrições foi o mais pesquisado; em 20IO/I e 20I2/I, o tema de lean production obteve o maior número de pesquisas, e, em 20II/I, as pesquisas abordaram em maior quantidade o tema de capacidade de instalações e equipamentos. Nesse período, o professor adquiriu maior habilidade na condução do jogo de empresas, ou seja, a partir de 2009/2, o contexto do jogo de empresas foi preponderante para a escolha de determinados temas de pesquisa em gestão de operações, e as variáveis do simulador tenderam a perder importância na escolha dos temas de pesquisa em gestão de operações. A maior variabilidade dos sete temas mais pesquisados nesse período constatada no Gráfico 3 evidencia, com os dados da Tabela I, o crescimento de novos temas e o decréscimo de temas preponderantes, com aquele referente à gestão de estoques. Os conhecimentos, as habilidades e atitudes do professor na condução do jogo de empresas podem ter favorecido a consideração de novos temas no transcorrer do jogo de empresas. Por exemplo, um incidente crítico de contaminação do meio ambiente por parte da indústria pode atrair a atenção dos gestores das empresas simuladas para assuntos relativos à sustentabilidade em gestão de operações.

Em síntese, o simulador utilizado no laboratório de gestão permitiu aos estudantes gerenciar explicitamente cinco variáveis de operações, o que facilitou $42 \%$ das pesquisas em torno desses temas. Variáveis não explícitas no simulador 
foram trabalhadas em $58 \%$ das pesquisas aplicadas que exploraram I4 novos temas, devido ao contexto do jogo de empresas. No entanto, existem variáveis não abordadas nas pesquisas aplicadas e que poderiam ser utilizadas no ambiente do laboratório de gestão. A evolução dos fatores condicionantes da escolha dos temas de pesquisa em gestão de operações revelou um período inicial (de 2005/I a $2007 / 2$ ) de estabilidade dos temas pesquisados em que as variáveis explícitas no simulador apresentavam maior relevância e um período posterior $(2009 / 2 \mathrm{e}$ $2013 / \mathrm{I}$ ), no qual ocorrem o surgimento de novos temas referentes ao contexto do jogo de empresas e maior variabilidade dos temas pesquisados.

O Quadro 7 revela a comparação entre os principais temas de gestão de operações estudados no laboratório de gestão, os temas de pesquisa tratados por pesquisadores brasileiros da área de gestão de operações na última década nas principais revistas brasileiras da área de administração e nos periódicos internacionais mais relevantes da área de gestão de operações elencados por Paiva e Brito (20I3), e os temas de gestão de operações que estão sendo valorizados atualmente pelas empresas mais expressivas na criação, utilização e disseminação de novos conceitos produtivos abordados no estudo de Peinado e Graeml (20I3).

QUADRO 7

COMPARAÇÃO ENTRE TEMAS ESTUDADOS NO LABORATÓRIO

DE GESTÃO E TEMAS PRIORITÁRIOS PARA A PESQUISA

E PARA EMPRESAS INOVADORAS

\begin{tabular}{lll}
\hline $\begin{array}{l}\text { TEMAS LABORATÓRIO } \\
\text { DE GESTÃO }\end{array}$ & $\begin{array}{l}\text { TEMAS PESQUISADOS } \\
\text { NAACADEMIA }\end{array}$ & $\begin{array}{l}\text { TEMAS VALORIZADOS } \\
\text { PELAS EMPRESAS }\end{array}$ \\
\hline Estoque & Cadeia de suprimentos & Lean production - just in time \\
\hline Teoria das restrições & Estratégia de operações & Gestão da qualidade \\
\hline $\begin{array}{l}\text { Logística e cadeia de } \\
\text { suprimentos }\end{array}$ & Desenvolvimento de produtos & $\begin{array}{l}\text { Gestão de pessoas em } \\
\text { operações }\end{array}$ \\
\hline Processos e produtos - P\&D & Programação da produção & Gerência de processos \\
\hline $\begin{array}{l}\text { Lean production - just in time } \\
\text { Capacidade - instalaçoes e } \\
\text { equipamentos }\end{array}$ & Operações de serviços & Projeto e medida do trabalho \\
\hline $\begin{array}{l}\text { Planejamento e controle } \\
\text { Gano da qualidade }\end{array}$ & Desempenho e produtividade \\
\hline
\end{tabular}

(continua) 
QUADRO 7 (CONCLUSÃO)

COMPARAÇÃO ENTRE TEMAS ESTUDADOS NO LABORATÓRIO

DE GESTÃO E TEMAS PRIORITÁRIOS PARA A PESQUISA

E PARA EMPRESAS INOVADORAS

\begin{tabular}{lll}
\hline $\begin{array}{l}\text { TEMAS LABORATÓRIO } \\
\text { DE GESTÃO }\end{array}$ & $\begin{array}{l}\text { TEMAS PESQUISADOS } \\
\text { NA ACADEMIA }\end{array}$ & $\begin{array}{l}\text { TEMAS VALORIZADOS } \\
\text { PELAS EMPRESAS }\end{array}$ \\
\hline Estratégia em operações & $\begin{array}{l}\text { Gestão da variedade } \\
\text { de produtos }\end{array}$ \\
\hline Custos de produção & Operações sustentáveis \\
\hline Gestão da qualidade & \\
\hline Eficiência operacional & \\
\hline Projeto e medida do trabalho & \\
\hline $\begin{array}{l}\text { Teoria econômica da } \\
\text { produção }\end{array}$ & \\
\hline ERP/MRP & \\
\hline $\begin{array}{l}\text { Sustentabilidade e } \\
\text { responsabilidade social }\end{array}$ & \\
\hline Carteira de projetos
\end{tabular}

Fonte: Adaptado de Paiva e Brito (20I3, pp. 59-60) e Peinado e Graeml (2013, pp. II-I2).

Verificou-se um desalinhamento entre os temas de gestão de operações mais pesquisados no laboratório de gestão, o interesse em pesquisa na área de gestão de operações e as práticas prioritárias para empresas. Enquanto o laboratório de gestão priorizou os estudos de gestão de estoques, a principal prioridade acadêmica foi a gestão da cadeia de suprimentos, e a prioridade da prática empresarial está relacionada à lean production. O segundo tema mais pesquisado no laboratório de gestão, teoria das restrições, não foi relacionado entre as prioridades acadêmicas e empresariais. Os temas lean production - just in time, gestão da qualidade e projeto e medida do trabalho são prioridades para a academia, para a prática empresarial e para o laboratório de gestão, o que indicou uma convergência de estudos nesses temas.

Essa comparação demonstrou que o laboratório de gestão apresentou abrangência na área de gestão de operações e pode ser utilizado para preencher as lacunas existentes entre teoria acadêmica e prática profissional, por meio da 
flexibilização do simulador e do jogo de empresas, redirecionando o caso empresarial e o jogo de empresas para assuntos prioritários, o que potencializaria a utilização do laboratório de gestão como um elo entre academia e organizações.

\section{CONSIDERAÇÕES FINAIS}

\subsection{CONCLUSÕES E CONTRIBUIÇÕES}

Neste estudo, foram investigados os temas referentes à gestão de operações pesquisados no ambiente do laboratório de gestão, os dois principais fatores condicionantes da escolha dos temas e o potencial do laboratório de gestão para a prática dos modelos de gestão de operações, no sentido de contribuir para a aprendizagem sobre temas dessa área e amenizar as dificuldades de balanceamento entre teoria e prática na formação em gestão de operações. Dessa maneira, foi possível considerar o laboratório de gestão como uma iniciativa capaz de proporcionar um ambiente de aprendizagem que busque integrar teoria e prática em gestão de operações, pois se verificou a utilidade do laboratório de gestão para a prática de conceitos em I9 temas distintos de gestão de operações, indicando possíveis avanços na área de ensino e aprendizagem desse tipo de gestão com a pesquisa em torno de temas ainda não pesquisados nesse ambiente.

Entre as principais constatações extraídas do presente estudo, destaca-se o simulador organizacional utilizado no laboratório de gestão que permite explorar cinco temas de operações, sendo responsável por $42 \%$ das pesquisas, e o contexto do jogo de empresas com potencial de direcionar $58 \%$ das pesquisas aplicadas abordando I4 temas. A análise da evolução dos fatores condicionantes da escolha dos temas de pesquisa em gestão de operações revelou o surgimento de novos temas referentes ao contexto do jogo de empresas e maior variabilidade dos temas pesquisados. No entanto, existem temas ainda não abordados nas pesquisas aplicadas e que poderiam ser utilizados no ambiente do laboratório de gestão ou por uma alteração nas variáveis do simulador ou no contexto do jogo de empresas, o que poderia aumentar o número de temas pesquisados em gestão de operações no laboratório de gestão.

Outra constatação relevante deste estudo foi o destaque de dez temas recorrentes nas pesquisas aplicadas elaboradas pelos estudantes de graduação, o que demonstra o potencial de aprendizagem gerado pelo laboratório de gestão em diferentes temas de gestão de operações, ou seja, os temas gestão de estoques, gestão de processos e produtos, capacidade de produção, planejamento e controle da produção, teoria das restrições, logística e gestão de cadeia de suprimentos, 
lean production, estratégia em operações, custos de produção e gestão da qualidade geraram interesse e estiveram presentes nesse ambiente de aprendizagem em gestão de operações. Contudo, o ambiente do laboratório de gestão apresenta potencial para possíveis avanços na área de gestão de operações por meio do aprofundamento nos seguintes temas: manutenção, eficiência operacional, projeto e medida do trabalho, teoria econômica da produção, ERP/MRP, sustentabilidade e responsabilidade social em operações, tomada de decisões em operações, inovação em gestão de operações e carteira de projetos.

Cabe destacar que a aprendizagem documentada nas pesquisas aplicadas reforça que a atividade vivencial em sala de aula propiciou uma variedade de situações e experiências enriquecedoras de convivência em grupo, decisões sob incerteza, emoções, desafios e, principalmente, a utilização da teoria na prática do laboratório de gestão. Os estudantes orientaram-se pelas teorias de gestão de operações estudadas em outras disciplinas e vivenciaram casos de sucesso e de fracasso na aplicação prática das teorias, corroborando ou refutando as teorias estudadas e gerando valor ou prejuízo à empresa no jogo de empresas, o que justifica a escolha de um problema e o esforço de realização de uma pesquisa.

Recomenda-se aos gestores e educadores a adoção desse modelo de educação gerencial e pesquisa, pois, no laboratório de gestão, a aprendizagem não se restringe ao ambiente do jogo de empresas, a aplicação prática dos modelos de gestão de operações pode ser transposta para as empresas reais, pois os gestores do futuro preparam-se vivenciando, na prática, I9 modelos teóricos de gestão de operações por meio dessa proposta inovadora. Este estudo destacou a importância da área de gestão de operações e do setor produtivo de uma empresa na busca de resultados, pois os impactos das decisões de operações afetam as características da empresa no jogo de empresas. Por isso, usar os modelos conceituais de gestão de operações nesse contexto envolve aprendizagem com significados, o que é diferente de uma aula expositiva de gestão de operações.

Uma das contribuições do estudo foi a sistematização dos temas de gestão de operações abordados no laboratório de gestão, com ordenação dos temas mais estudados e dos temas com potencial a serem explorados e dos temas que podem ser incorporados ao simulador ou ao jogo de empresas para serem investigados pelos estudantes nas pesquisas aplicadas.

A verificação da aplicação das teorias de gestão de operações no laboratório de gestão é outra contribuição deste estudo, uma evidência de que as teorias funcionaram nesse ambiente laboratorial e podem ser replicadas em outros ambientes. Desse modo, I9 modelos teóricos estiveram presentes no laboratório de gestão, os quais apresentam potencial para possíveis avanços na área de gestão de operações no que tange ao ensino e à aprendizagem com pesquisa em torno de temas ainda não pesquisados nesse ambiente. 


\subsection{LIMITAÇÕES E PROPOSIÇÕES PARA NOVOS ESTUDOS}

Por mais significativa que seja a produção de pesquisas aplicadas no ambiente do laboratório de gestão na área de gestão de operações, são necessários estudos que tragam indagações e pesquisas complementares nesse contexto, a fim de proporcionar maiores informações sobre a qualidade das pesquisas aplicadas produzidas pelos estudantes de graduação, o que pode despertar maior interesse em estudos de gestão de operações no ambiente do laboratório de gestão.

Uma das limitações presentes no estudo foi a classificação dos temas referentes à gestão de operações, já que os frameworks de excelência em manufatura propostos por pesquisadores, consultores, agências e empresas são distintos e apresentam diversas peculiaridades. Essa limitação foi reconhecida no transcorrer da pesquisa, e seus efeitos foram atenuados por meio da análise comparativa dos quadros existentes e da busca por autores de reconhecida importância em suas respectivas áreas de atuação dentro do escopo da gestão de operações.

Os limites econômicos das regras do simulador restringiram algumas possibilidades adicionais que poderiam ter sido utilizadas na aplicação dos conceitos, das técnicas e das ferramentas de gestão de operações, o que pode ser mitigado pela condução do jogo de empresas, pois o modelo é uma simplificação da realidade, mas os conhecimentos, as habilidades e atitudes do professor e dos estudantes podem superar essas limitações inerentes aos jogos de empresas apoiados por modelos simplificados da realidade empresarial.

O laboratório de gestão oferece uma perspectiva de educação gerencial que abrange o processo de tomada de decisões gerenciais em seis áreas funcionais: presidência, planejamento, gestão de pessoas, marketing, finanças e produção. Novos estudos podem contribuir para a aprendizagem sobre temas de gestão de pessoas, marketing, finanças, presidência e planejamento, verificando os temas referentes a cada área funcional pesquisados no ambiente do laboratório de gestão, os principais fatores condicionantes da escolha dos temas e o potencial do laboratório de gestão para a prática dos modelos de cada uma das cinco áreas não abrangidas neste estudo.

Novos estudos podem manter o foco na gestão de operações dentro do laboratório de gestão, no sentido de considerar novas variáveis de gestão de operações no simulador que apoia o jogo de empresas, na tentativa de aproximá-lo ainda mais do ambiente das empresas reais. Algumas alternativas poderiam ser: ampliação e diversificação do número de fornecedores, inserção de variáveis ambientais voltadas às operações ou programação, sequenciamento e acompanhamento da produção no curto prazo. Isso poderia servir de fonte de enriquecimento para novas pesquisas de gestão de operações no ambiente do laboratório de gestão. 
Outras pesquisas podem surgir com o processo de construção de modelos conceituais, matemáticos e computacionais de um simulador específico para a área de gestão de operações, abrangendo maior número de variáveis específicas de operações, o que poderia ampliar o escopo de estudo para além dos temas de operações abordados atualmente no ambiente do laboratório de gestão, transformá-lo em um laboratório de gestão de operações voltado especificamente para os gestores interessados na área de gestão de operações e ampliar o escopo do laboratório para outras áreas, como a engenharia de produção.

\section{PRACTICING OPERATIONS MANAGEMENT IN A LABORATORY MANAGEMENT}

\section{ABSTRACT}

Describing models of operations management is not sufficient to illustrate its dynamism, complexity and importance. The lack of proper balance between theory and practice in education regarding operations management suggests the search for initiatives that provide a learning environment that integrates theory and practice. Thus, the objective is to verify the issues relating to operations management surveyed in the environment of laboratory management, the main factors affecting the choice of topics, and the potential of the laboratory management for the practice of operations management models. This study discusses the models of operations management related to the themes in operations strategy, supply chain management, quality management, maintenance, lean production, sustainability, management of processes and products, innovation, inventory management, production capacity, theory of constraints, planning and production control, production costs, design and measurement of work, enterprise resource planning/manufacturing resource planning (ERP/MRP), project portfolio and laboratory management supported by the conceptual tripod: simulator, business game and applied research. According to the classification proposed by Gonçalves (2007), we performed a descriptive analysis of the laboratory management, adopting the method of longitudinal case study, within a quantitative approach, in the perspective of a bibliometric survey. The data collected and analyzed correspond to nine years (2005-20I3) driving laboratory management in a public university. The simulator used in laboratoy management enabled students to manage five variable explicitly operations, which facilitated $42 \%$ of research focused on these themes. Non-explicit variablesin the simulator 
were used in $58 \%$ of applied research, exploring I4 new themes, due to business game. However, there are variables not addressed in applied research that could be used in the environment of the laboratory management. The usefulness of the laboratory management to practice concepts of operations management was verified, indicating possible advances in the area of teaching and learning operations management with research on under-researched or non-researched topics in this environment of management education.

\section{KEYWORDS}

Operations management. Laboratory management. Learning. Business games. Simulator.

\section{LA PRÁCTICA DE LA GESTIÓN DE OPERACIONES EN UN LABORATORIO DE GESTIÓN}

\section{RESUMEN}

Describir los modelos de la gestión de operaciones no es suficiente para ilustrar su dinamismo, complejidad e importancia. Las dificultades de equilibrio entre la teoría y la práctica en materia de educación en gestión de operaciones sugiere la búsqueda de iniciativas que proporcionen un ambiente de aprendizaje que integre la teoría y la práctica. De esa forma, el objetivo es verificar las cuestiones relativas a la gestión de operaciones investigadas en el ambiente del laboratorio de gestión, los principales factores que afectan la elección de los temas, y el potencial del laboratorio de gestión para la práctica de los modelos de gestión de operaciones. Este estudio analiza los modelos de las operaciones relacionadas con los temas de estrategia de operaciones, supply chain management, gestión de calidad, mantenimiento, producción lean, sostenibilidad, gestión de procesos y productos, innovación, gestión de inventario, capacidad de producción, teoría de las restricciones, planificación y control de producción, costos de producción, proyecto y medida del trabajo, ERP/MRP, cartera de proyectos y el laboratorio de gestión apoyado en el trípode conceptual: simulador, juegos de empresas e investigación aplicada. De acuerdo con la clasificación propuesta por Gonçalves (2007), se realizó un análisis descriptivo del laboratorio de gestión, adoptando el método de estudio de casos longitudinal con enfoque cuantitativo, en la perspectiva de una investigación bibliométrica. Los datos recogidos y analizados 
corresponden a nueve años (2005-2013) de prácticas del laboratorio de gestión en una universidad pública. El simulador utilizado en el laboratorio de gestión permitió que los estudiantes manejaran cinco variables de operaciones explícitamente, lo que facilitó el $42 \%$ de la investigación en torno a estos temas. Las variables que no fueron explícitas en el simulador han sido trabajadas en el $58 \%$ de las investigaciones aplicadas cubriendo i4 nuevos temas, debido a los juegos de empresas. Sin embargo, hay variables no abordadas en las investigaciones aplicadas que podrían ser utilizadas en el laboratorio de gestión. Se constató la utilidad del laboratorio de gestión para practicar los conceptos de operaciones, lo que indica posibles avances en el ámbito de la enseñanza y el aprendizaje de la gestión de operaciones con la investigación sobre temas poco investigados o no investigados aún en este entorno de educación para la gestión.

\section{PALABRAS CLAVE}

Gestión de operaciones. Laboratorio de gestión. Aprendizaje. Juegos de empresas. Simulador.

\section{REFERÊNCIAS}

Araújo, C. A. (2006). Bibliometria: evolução histórica e questões atuais. Em Questão, 12(I), II-32. Barney, J. B. (I995). Looking inside for competitive advantage. Academy of Management Executive, 9(4), 49-6r.

Baudin, M. (2010). Lean logistics. New York: Productivity Press.

Bligh, D. A. (2000). What's the use of lectures? San Francisco: Jossey-Bass.

Bloom, N., \& Reenen, J. V. (20I0). Why do management practices differ across firms and countries? Journal of Economic Perspectives, 24(I), 203-224.

Caro, F., Gallien, J., Díaz, M., García, J., Corredoira, J. M., Montes, M., Ramos, J. A., Correa, J. (2010). Zara uses operations research to reengineer its global distribution process. Interfaces, 40(I), 7I-84. Christensen, C. M., Suárez, F. F., \& Utterback, J. M. (I998). Strategies for survival in fast-changing industries. Management Science, 44(12), 207-220.

Cooper, R. G., Edgett, S., \& Kleinschmidt, E. (200I). Portfolio management for new product development: results of an industry practices study. R\&D Management, 31(4), 36I-380.

Faria, A. J., Hutchinson, D., Wellington, W. J., \& Gold, S. (2009). Developments in business gaming: a review of the past 40 years. Simulation \& Gaming, 40(4), 464-487.

Gautam, R., Kadyan, S., \& Ohlan S. (20I2). Comparison of JIT with other industrial production approaches: a review. International Journal of Scientific \& Engineering Research, 3(10), I-7.

Gil, A. C. (2009). Didática do ensino superior. São Paulo: Atlas.

Gino, F., \& Pisano, G. (2008). Toward a theory of behavioral operations. Manufacturing \& Service Operations Management, 10(4), 676-691. 
Gonçalves, E. P. (2007). Iniciação a pesquisa científica (4a ed.). Campinas: Alínea, 2007.

Gonçalves, M. A. (2009). A racionalidade dos processos de interdependência organizacional em rede. In M. J. B. Franco, J. C. C. Leitão, F. A. S. Almeida \& A. T. R. Guimarães (Eds.). Cooperação entre empresas, clusters, redes de negócios e inovação tecnológica (pp. I9I-2II). Portugal: Covilhã.

Halldorsson, A., Kotzab, H., Mikkola, J. H., \& Larsen, T. S. (2007). Complementary theories to supply chain management. Supply Chain Management: An International Journal, 12(4), 284-296.

Hayes, R. H., Pisano, G., Upton, D., \& Wheelwright, S. (2008). Produção, estratégia e tecnologia: em busca da vantagem competitiva. Porto Alegre: Bookman.

Jabbour, C. J. C., Silva, E. M., Paiva, E. L., \& Santos, F. C. A. (2012). Environmental management in Brazil. Is it a completely competitive priority? Journal of Cleaner Production, 21(I), II-22.

Kleindorfer, P. R., Singhal, K., \& Wassenhove, L. N. V. (2005). Sustainable operations management. Production and Operations Management, 14(4), 482-492.

Kolb, D. A. (I984). Experiential learning: experience as the source of learning and development. Englewood Cliffs: Prentice Hall.

Llach, J., Casadesus, M., \& Marimon, F. (20II). Relationship between quality-management systems and organizational innovations. Human Factors and Ergonomics in Manufacturing \& Service Industries, 21(I), 52-66.

Minkman, M., Ahaus, K., \& Huijsman, R. (2007). Performance improvement based on integrated quality management models: what evidence do we have? A systematic literature review. International Journal for Quality in Health Care, 19(2), 90-104.

Nascimento, P. T. S. (2013). Portfolio generation goes beyond project selection: interdependencies must drive new alternatives creation. Gestão \& Produção, 20(I), I3-22.

Paiva, E. L., \& Brito, L. A. L. (20I3). Produção científica brasileira em gestão de operações no período 2000-2010. Revista de Administração de Empresas, 53(I), 56-66.

Peinado, J., \& Graeml, A. R. (2013). A prática da gestão de operações nas organizações. Anais do Simpósio de Administração da Produção, Logística e Operações Internacionais, São Paulo, SP, Brasil, I6. Sauaia, A. C. A. (I995). Satisfação e aprendizagem em jogos de empresas: contribuições para aprendizagem gerencial. Tese de doutorado, Universidade de São Paulo, São Paulo, SP, Brasil.

Sauaia, A. C. A. (2006). Lógica econômica, raciocínio estratégico e evolução organizacional: além das regras do jogo de empresas. Tese de livre-docência, Universidade de São Paulo, São Paulo, SP, Brasil. Sauaia, A. C. A. (2009). Monografia racional: uma versão eletrônica. Revista Eletrônica de Gestão, 2(I), I66-I68.

Sauaia, A. C. A. (2010). Laboratório de gestão: simulador organizacional, jogo de empresas e pesquisa aplicada (2a ed.). Barueri: Manole.

Senge, P. (2005). A quinta disciplina. (Iga ed.). São Paulo: Best Seller.

Severino, A. J. (2007). Metodologia do trabalho científico (23a ed.). São Paulo: Cortez.

Shah, R., \& Ward, P. T. (2003). Lean manufacturing: context, practice bundles, and performance. Journal of Operations Management, 21(2), I29-I49.

Sharma, M., \& Kodali, R. (2008). Development of a framework for manufacturing excellence. Measuring Business Excellence, 12(4), 50-66.

Slack, N. (2005). Operations strategy: will it ever realize its potential? Gestão e Produção, 12(3), 323-332. Slack, N., Chambers, S., \& Johnston, R. (2008). Administração da produção (2a ed.). São Paulo: Atlas. 
Slack, N., Lewis, M. A., \& Bates, H. (2004). The two worlds of operations management research and practice: can they meet, should they meet? International Journal of Operations and Production Management, 24(4), 372-387.

Sprague, L. G. (2007). Evolution of the field of operations management. Journal of Operations Management, 25(2), 219-238.

Summers, G. J. (2004). Today's business simulation industry. Simulation \& Gaming, 35(2), 208-24I. Tao, Y. H., Cheng, C. J., \& Sun, S. Y. (2009). What influences college students to continue using business simulation games? The Taiwan experience. Computers \& Education, 53(3), 929-939.

Wheelwright, S. C., \& Clark, K. B. (I992). Creating project plans to focus product development. Harvard Business Review, 70(2), 70-72.

Womack, J. P., \& Jones, D. T. (I996). Lean thinking: banish waste and create wealth in your corporation. New York: Simon \& Schuster.

Zilbovicius, M. (I999). Modelos para a produção, produção de modelos: gênese, lógica e difusão do modelo japonês de organização da produção. São Paulo: Annablume. 